\title{
Exfoliation effect of PEG-type surfactant on Pd supported GO (SE-Pd(nanoparticle)/GO) in cascade synthesis of amides; a comparison with $\mathrm{Pd}($ nanoparticle)/rGO
}

Sadegh Rostamnia, ${ }^{\mathrm{a}, *}$ Esmail Doustkhah, ${ }^{\mathrm{a}, \mathrm{b}}$ Behzad Zeynizadeh ${ }^{\mathrm{b}, *}$

${ }^{a}$ Organic and Nano Group (ONG), Department of Chemistry, Faculty of Science, University of Maragheh, PO Box 55181-83111, Maragheh, Iran. Tel:+98(421) 2276066; Fax: +98(421) 2276066; Email: rostamnia@maragheh.ac.ir; srostamnia@gmail.com

${ }^{b}$ Department of Chemistry, Faculty of Science, Urmia University, Urmia 57159-165, Iran. Tel:+98(441)2972035; Fax: +98(441)2753172; Email: bzeynizadeh@gmail.com

\begin{abstract}
In the presence investigation, a cascade method for the synthesis of primary amides is discussed by the catalysis of $\mathrm{Pd}$ supported onto graphene oxide $(\mathrm{Pd} / \mathrm{GO})$ nanosheets. Also, the effect of different polyethyleneglycol-type (PEG-type) polyethers including PEG-300, P123 and F127 on the catalytic activity of $\mathrm{Pd} / \mathrm{rGO}$ is studied in the the reaction of aldehyde and hydroxylamine hydrochloride to give benzamide. Addition of PEG-type polyethers played an important role in raising the catalytic power of $\mathrm{Pd}($ nanoparticle $) / \mathrm{GO}$ by exfoliation of $\mathrm{GO}$ sheets. The present paper introduces $\mathrm{Pd}($ nanoparticle)/GO as first $\mathrm{Pd}$ supported $\mathrm{GO}$ for the synthesis of primary amides through this method. This catalyst was highly active, efficient, tolerant, and environmentally benign in one-pot conditions with recyclability at least for 8 runs. Also, this study suggests the prevailing catalytic activity of $\mathrm{Pd}($ nanoparticle)/GO rather to $\mathrm{Pd}($ nanoparticle $) / \mathrm{rGO}$ in a comparitive experiment.
\end{abstract}

Keywords: Cascade amidation; $\mathrm{Pd}($ nanoparticle)/GO; reduced graphene oxide; polyethers; exfoliation. 


\section{Introduction}

Amide functional groups are placed within a vast range of crucial organic materials including polymers, peptides, protein, and pharmaceutical compounds [1]. Synthesis of amides by traditional procedures through the reaction of carboxylic acids (or their activated derivatives such as chlorides, anhydrides or esters) and amine, could be inconvenient and unselective in a total synthesis or a densely functionalized compounds. Hence, many other methods are developed [24]. Among them and based on "green chemistry" desire, cascade-type and tandem amidation processes are the considerable part of recent developments. Their easier economical processing, costly-reasonable and available starting materials are the advantages to others. Some catalysts are developed for efficient synthesis of amides [5-8]. However, most of the catalysts could not be recovered and reused for next times. Recently we developed copper grafted SBA-15 as a recyclable catalyst in amidation reaction using aldehydes, hydroxylamine hydrochloride in a basic condition [9]. Now, due to the fact that basic condition is not suitable for silica structure of SBA-15 support, we aimed to extend our research area to new types of catalytic systems based on Pd which can be produced and stabilized by efficient carbon-based materials such as graphene oxide (GO) and reduced graphene oxide ( $\mathrm{rGO}$ ) nanosheets.

Pd-based heterogeneous nanocatalysts [10] is of our interests which are previously developed by our group [11-15]. Pd based nanocatalysts are generally used in C-C and X-C (X = N, S, O) coupling reactions such as $\mathrm{C}-\mathrm{N}$ bond coupling (e.g. primary amide and arylhalide) [16]. However, there are few reports that a Pd-based material has catalyzed the synthesis of primary amides through the condensation of hydroxylamine hydrochloride and benzaldehyde in a cascade method. On the other side, Pd-based catalysts suffer from aggregation and deactivation in each 
run [17-19]. Necessity of Pd species engagement with a suitable ligand or support is inevitable in order to obtain an efficient, recyclable, and atom efficient catalyst [20-24].

$\mathrm{Pd} /$ carbon based materials are promising catalysts in Pd-catalyzed reaction from the point view of their recyclability, high yield of production and stability of the catalyst in harsh acid/base conditions [25]. Due to suitable interaction of Pd species with carbon based structures, $\mathrm{Pd}$ deposition happens on the surface of carbon based materials. Bulkier types of Pd/carbon catalysts may suffer from higher catalytic amount of $\mathrm{Pd} /$ carbon and their lower recyclability and therefore earlier aggregation of $\mathrm{Pd}$ species [26-28]. Deposition of $\mathrm{Pd}$ on graphene oxide $(\mathrm{Pd} / \mathrm{GO})$ and reduced graphene oxide $(\mathrm{Pd} / \mathrm{rGO})$ are of efficient methods rather to other $\mathrm{Pd} /$ carbon based catalysts [29-32]. However in comparison, $\mathrm{rGO}$ and $\mathrm{Pd} / \mathrm{rGO}$ nanosheets exhibit more tendency to self-assembly rather to $\mathrm{GO}$ and $\mathrm{Pd} / \mathrm{GO}$ in relatively higher concentrations and temperatures especially in $\mathrm{H}_{2} \mathrm{O}$. This may restrict the efficiency of $\mathrm{Pd} / \mathrm{rGO}$ in some cases by decreasing the catalytic surface area. Recently in our group, we have established the study of $\mathrm{Pd} / \mathrm{GO}$ and $\mathrm{Pd} / \mathrm{rGO}$ exfoliation by surfactant and their catalytic activity in the presence of various surfactants. In this work, we found that addition of poly ethyleneglycol-type (PEG-type) polyetheric surfactant during the catalysis of $\mathrm{Pd}($ nanoparticle)/rGO makes a remarkable change in the catalytic activity.

Transition metal-catalysed rearrangement of aldoxime to amide, which is usually catalyzed by transition metal ions such as $\mathrm{Cu}$ [33], $\mathrm{Zn} \mathrm{[34],} \mathrm{Ru}$ [35], $\mathrm{Rh}$ [36], and $\mathrm{Au}$ [37], is a strategy of primary amide synthesis. In the present paper, we have studied the catalytic activity of Pd supported GO in the presence of different PEG-type polyethers. In this cascade method, synthesis of primary amides from simple aromatic aldehydes and hydroxyl amine were accomplished. To the best of our knowledge, this is the first report of a Pd supported catalyst in 
the synthesis of primary amides through this reaction pathway. Homogeneous $\mathrm{Pd}(\mathrm{OAc})_{2}$ salt is the only Pd-based catalyst for the direct conversion of benzaldehyde to benzamide [38]. Hence, we applied PEG-type polyethers for intense exfoliation of $\mathrm{Pd} / \mathrm{GO}$ to acquire homogeneous behaviour on this catalyst while keeping itself a recoverable and reusable catalyst.

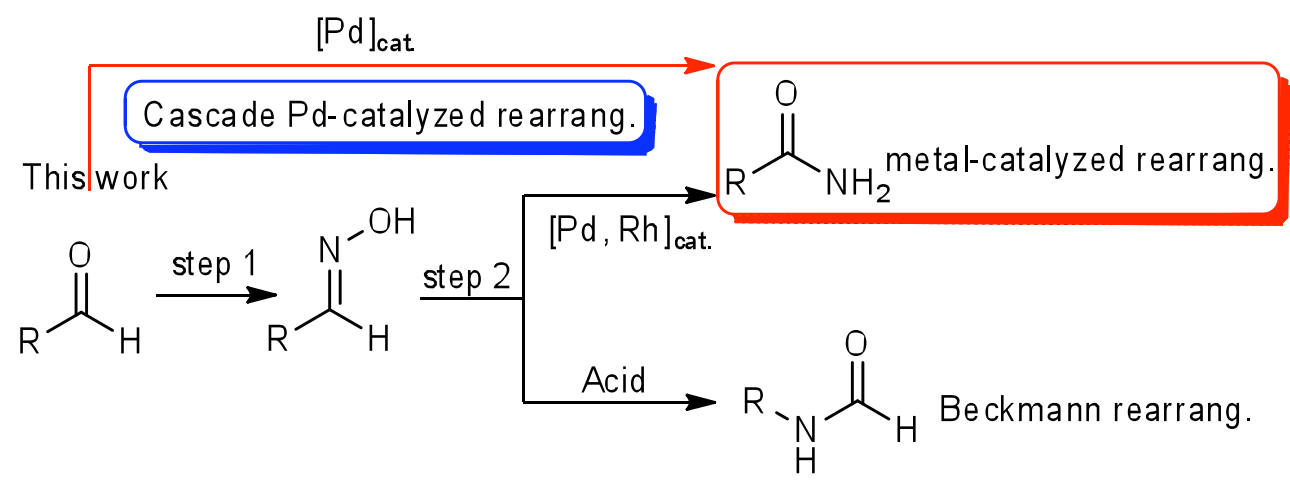

Scheme 1. Rearrangements of oximes to amides and cascade amidation.

\section{Results and Discussion}

\section{Catalyst synthesis and characterization}

Synthesis of the catalyst, $\mathrm{Pd}($ nanoparticle)/GO, was achieved by oxidizing the graphitic carbon to graphene oxide following our method $[13,15]$. Then, in the presence of ultrasonic irradiation (for exfoliation of GO), Pd species were supported onto GO sheets. For the synthesis of $\mathrm{Pd}($ nanoparticle)/rGO, the reduction of $\mathrm{GO}$ and $\mathrm{Pd}$ ions were performed through addition of $\mathrm{NaBH}_{4}$ as a reductant. However after reduction, tendency towards aggregation of graphene sheets was high. Sonication of the solution before addition of Pd source has a drastic effect on the uniform distribution of Pd particles onto surface of well exfoliated graphene sheets. On the other hand, using ultrasonic irradiation during the reaction for long-time reactions is restricted and is not suitable. Therefore to keep the $\mathrm{Pd}$ (nanoparticle)/GO and $\mathrm{Pd}$ (nanoparticle)/rGO sheets exfoliated, we used polyethers to stabilize the exfoliation state of these sheets. For example, the obtained $\mathrm{Pd}\left(\right.$ nanoparticle)/GO was kept exfoliated by surfactant of $\mathrm{F} 127$, to produce $\mathrm{SE}_{\mathrm{F} 127^{-}}$ 
$\mathrm{Pd}_{\text {(nanoparticle/GO }}$. A general synthetic pathway for the synthesis of $\mathrm{SE}_{\mathrm{F} 127^{-}}$ $\mathrm{Pd}($ nanoparticle)/GO is illustrated in Scheme 1.

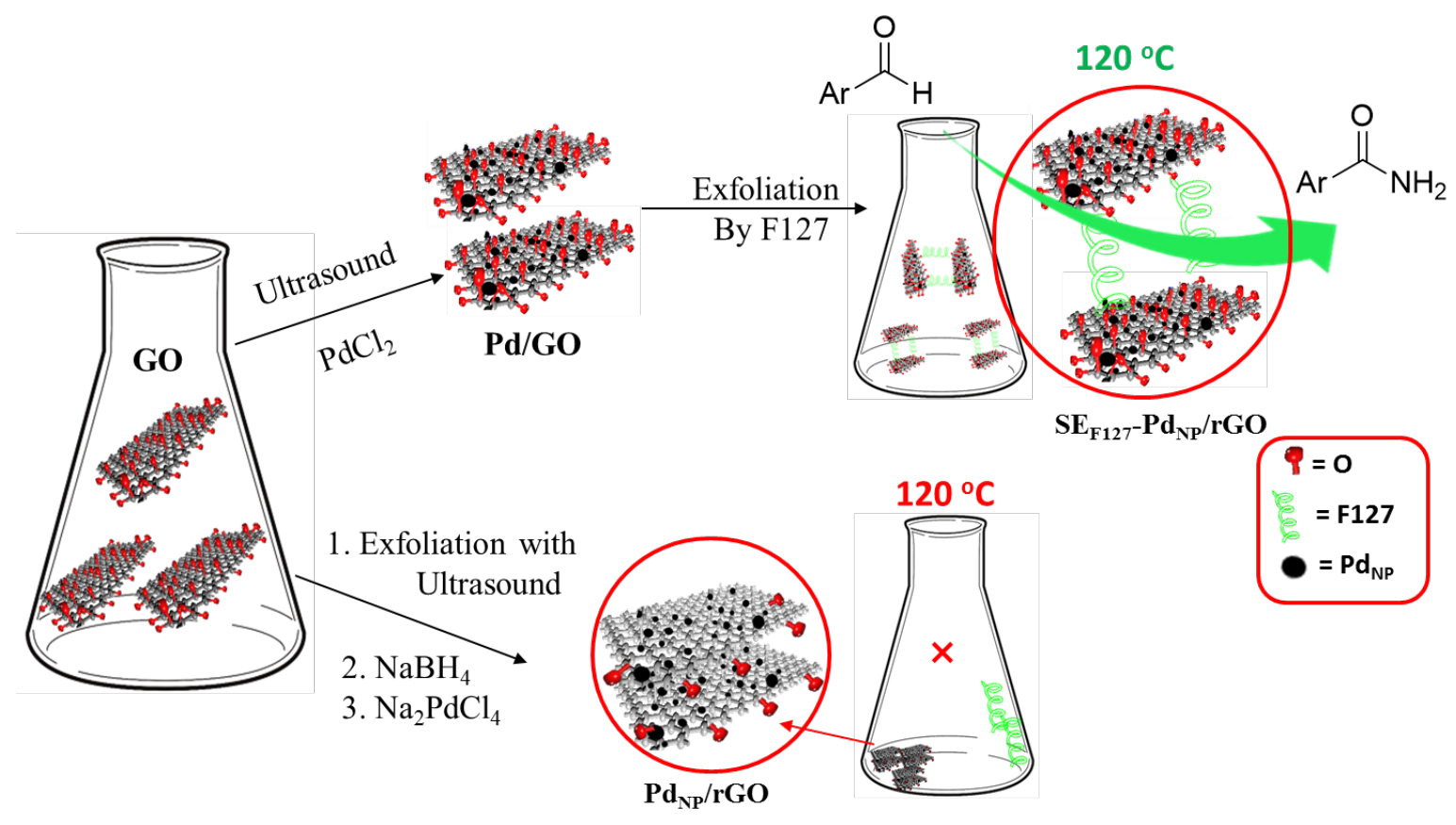

Scheme 2. Preparation and application of $\mathrm{SE}_{\mathrm{F} 127} \mathrm{Pd}($ nanoparticle)/GO.

To characterize the physicochemical properties of the Pd(nanoparticle)/GO, FTIR spectroscopy, X-ray diffraction (XRD), scanning electron microscopy (SEM), transmission electron microscopy (TEM), X-ray analysis (SEM-EDS) and atomic absorption spectroscopy (AAS) were applied. To our surprize, supporting $\mathrm{Pd}^{2+}$ leads to reduction and supporting of $\mathrm{Pd}$ nanoparticles on the surface of GO as observed by SEM and TEM images. Accordingly, in this material, Pd nanoparticles are dispersed on the surface of GO nanosheets. The estimated average particle size of deposited Pd nanoparticles by SEM and TEM is around 15-22 nm (Figure 1 and Figure 2). The particle size histogram of $\mathrm{Pd}($ nanoparticle $) / \mathrm{rGO}$ shows that particle size ranged from $14 \mathrm{~nm}$ to $23 \mathrm{~nm}$ (Fig. $1 \mathrm{~b}$ and Fig. 2b). 

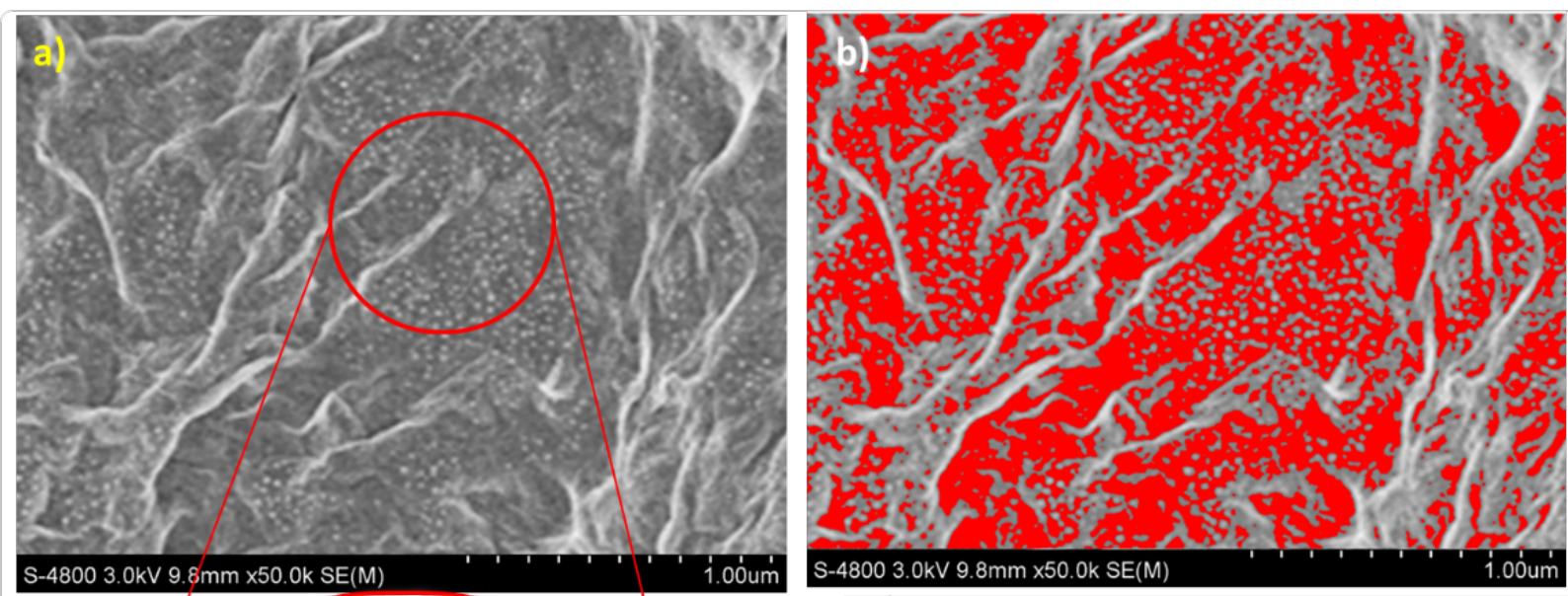

c)

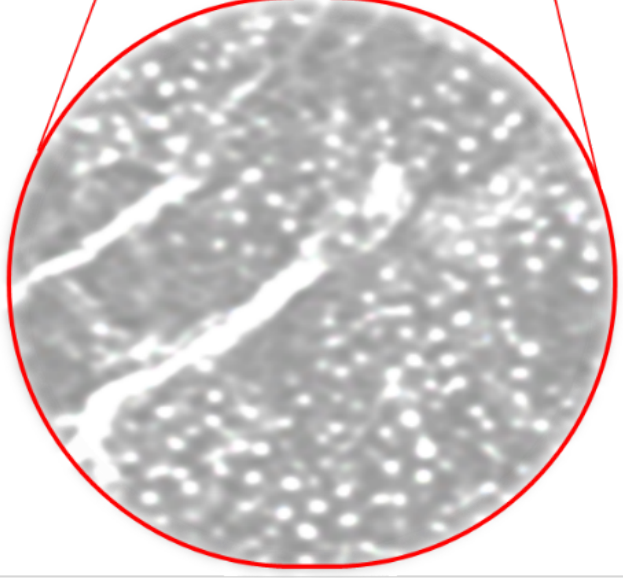

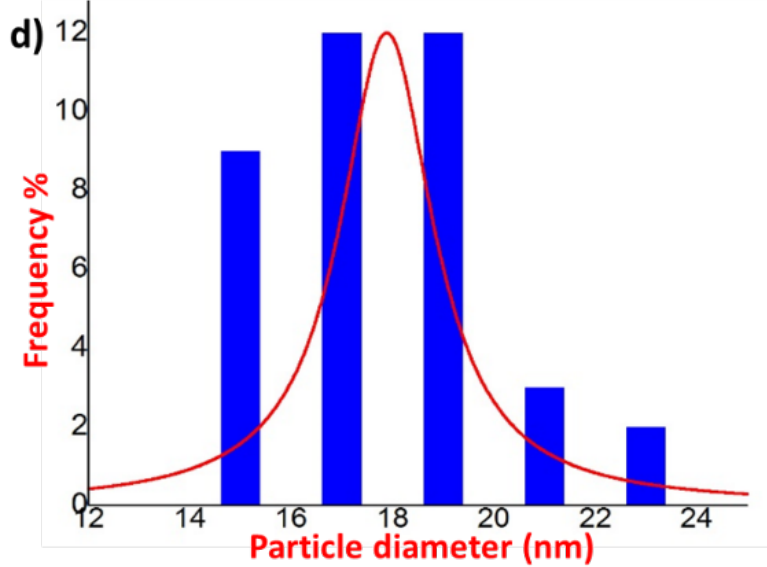

Fig. 1. SEM image (a), Binary-SEM (b) and reflected/zoomed SEM Pd(nanoparticle)/GO and its (d) particle size histogram.
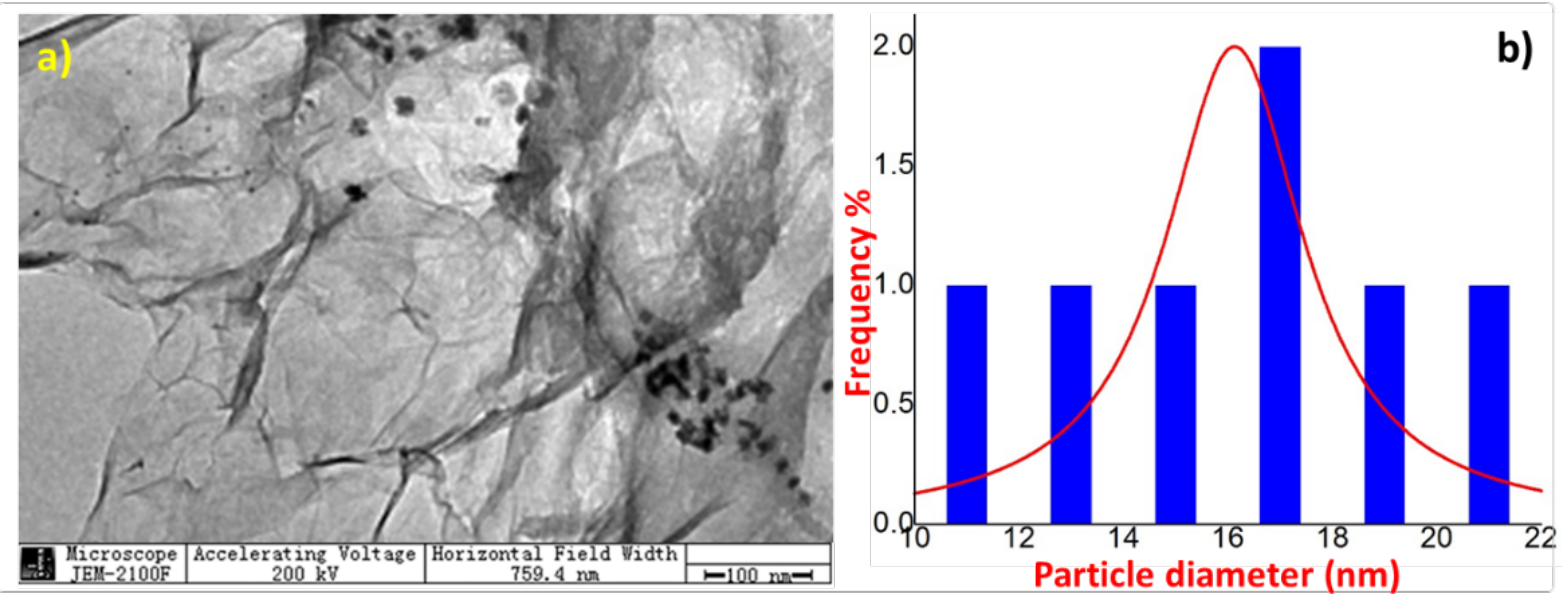

Fig. 2. TEM image (a) and its particle size histogram (b). 
Fig. 3a shows the XRD patterns of Pd(nanoparticle)/rGO and Pd(nanoparticle)/GO. SEM-EDS of $\mathrm{Pd}($ nanoparticle)/GO is also shown in this figure. SEM-EDS analysis was performed to confirm the composition of the as-prepared products (Figure 3b). Accordingly, a wide peak around $2 \theta=24^{\circ}$ could be assigned to rGO sheets [39], which in the case of $\mathrm{Pd}($ nanoparticle)/GO, the wide peak can be observed around $2 \theta=10^{\circ}$. A peak around $2 \theta=10^{\circ}$ can be also assigned to GO sheets in Fig 3a. The EDS analysis, the elemental analysis, confirms the existence of elements $\mathrm{Pd}, \mathrm{C}$ and $\mathrm{O}$ in $\mathrm{Pd}($ nanoparticle)/GO.

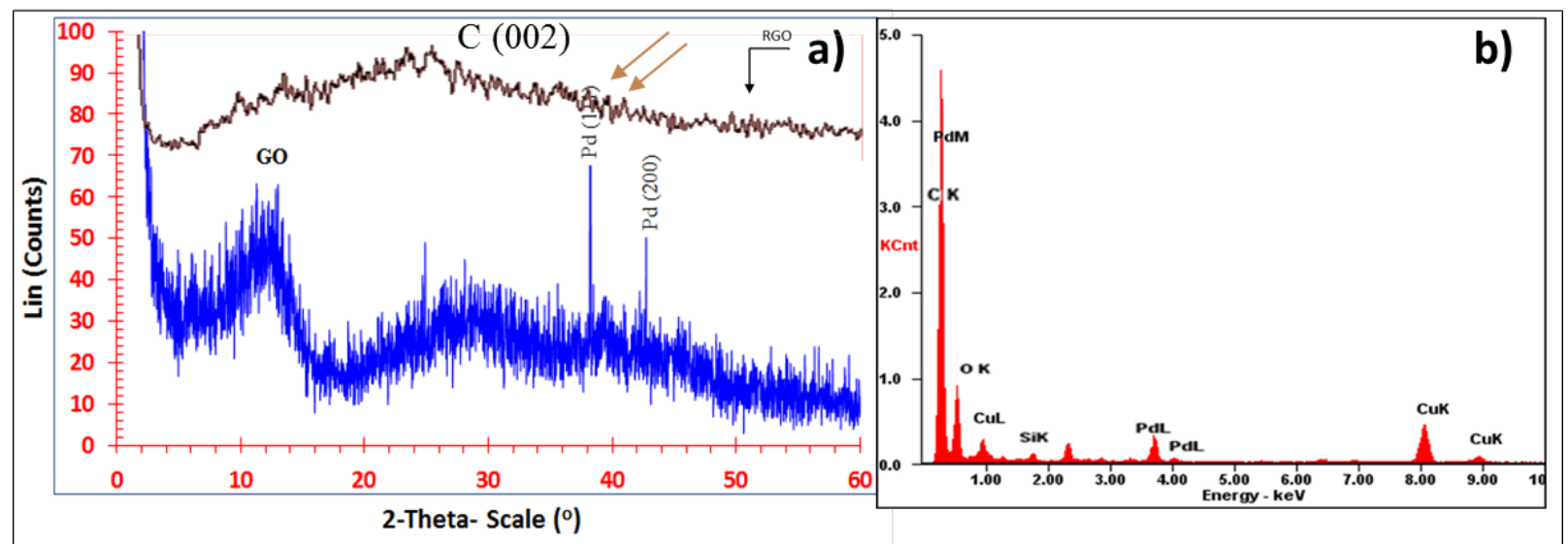

Fig. 3. XRD patterns of Pd(nanoparticle)/GO and Pd(nanoparticle)/rGO (a). SEM-EDX of $\operatorname{Pd}($ nanoparticle)/GO (b).

Comparison of FTIR spectrum of $\mathrm{Pd}($ nanoparticle)/rGO and $\mathrm{Pd}($ nanoparticle)/GO exhibits the formation and preservation of rGO chemical structure after Pd supporting. In FTIR of $\operatorname{Pd}\left(\right.$ nanoparticle) $/ \mathrm{rGO}$, a broad band at $3431 \mathrm{~cm}^{-1}$ may be attributed to the hydroxyl and carboxylic groups. A peak at $1108 \mathrm{~cm}^{-1}$ can be assigned to C-O bonds. A peak at $1574 \mathrm{~cm}^{-1}$ is owing to $\mathrm{C}=\mathrm{O}$ bonds. Some peaks in the range of $2870-2969 \mathrm{~cm}^{-1}$ relates to the existence of aliphatic $\mathrm{C}-\mathrm{H}$ bonds which are generated following to reduction of some groups in $\mathrm{GO}$ (Figure 4). 


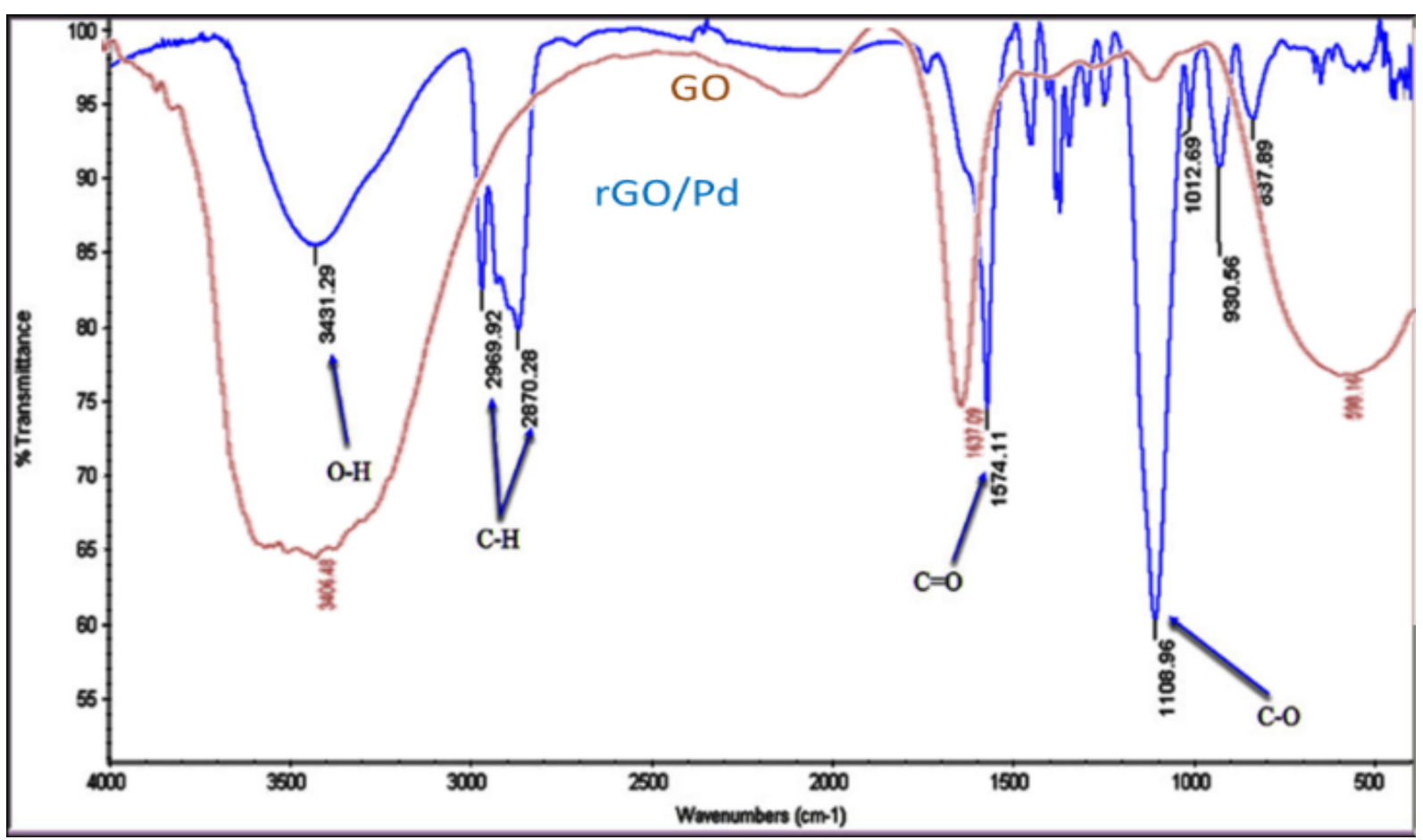

Fig. 4. FTIR spectra of $\mathrm{Pd}($ nanoparticle)/GO and $\mathrm{Pd}($ nanoparticle)/rGO.

\section{Catalyst tests}

For cascade amidation, as expected, we needed for well-exfoliation of $\mathrm{Pd}($ nanoparticle)/GO sheets followed by excellent catalysis. Thus, we chose three types of PEG-type polyethers to exfoliate $\mathrm{Pd}$ (nanoparticle)/GO sheets during the catalysis, which includes triblock copolymers of PEO-PPO-PEO (P123 and F127) and pure polyethylene glycol (PEG-300). The only difference between P123 and F127 is in their number of monomers, in which F127 (average number of monomers $=265)$ has a longer chain compared to P123 (average number of monomers $=110$ ). And the main difference between PEG-300 with two of P123 and F127 is that the later ones have propylene at the middle and ethylene at both sides while in the case of PEG-300, a homopolymer of ethylene oxide with 300 monomers can be found.

The presence of propylene causes to produce a hydrophobicity at the middle (propylene motif) of P123 and F127 and different micellar behaviours in aqueous phase while PEG-300 doesn't have 
such property [40]. Regarding to these differences, they were added to solution of $\mathrm{Pd}($ nanoparticle)/GO to monitor their impact on exfoliation and catalytic behaviour of $\operatorname{Pd}($ nanoparticle)/GO sheets in the amidation of benzaldehyde under the similar conditions. $\mathrm{Pd}($ nanoparticle)/GO sheets tend to aggregate and self-assemble in the absence of ultrasonic (US) or any additive. These three polyethers can well-exfoliate the $\operatorname{Pd}($ nanoparticle)/GO sheets in the absence of any reactants which are similar, while in the presence of reactants and other additives, F127 acted well both in exfoliation and catalytic activity. This result shows that the higher number of monomers rather to P123 has a drastic effect on the obtained results. Also in the case of PEG-300, which their number are near, in spite of well-exfoliation of $\mathrm{Pd}($ nanoparticle)/GO sheets it shows that the middle hydrophobic block of F127 and side blocks' hydrophilicity have made a balance in hydrophobicity and hydrophilicity of the reaction media which indeed both are indispensable (Fig. 5).

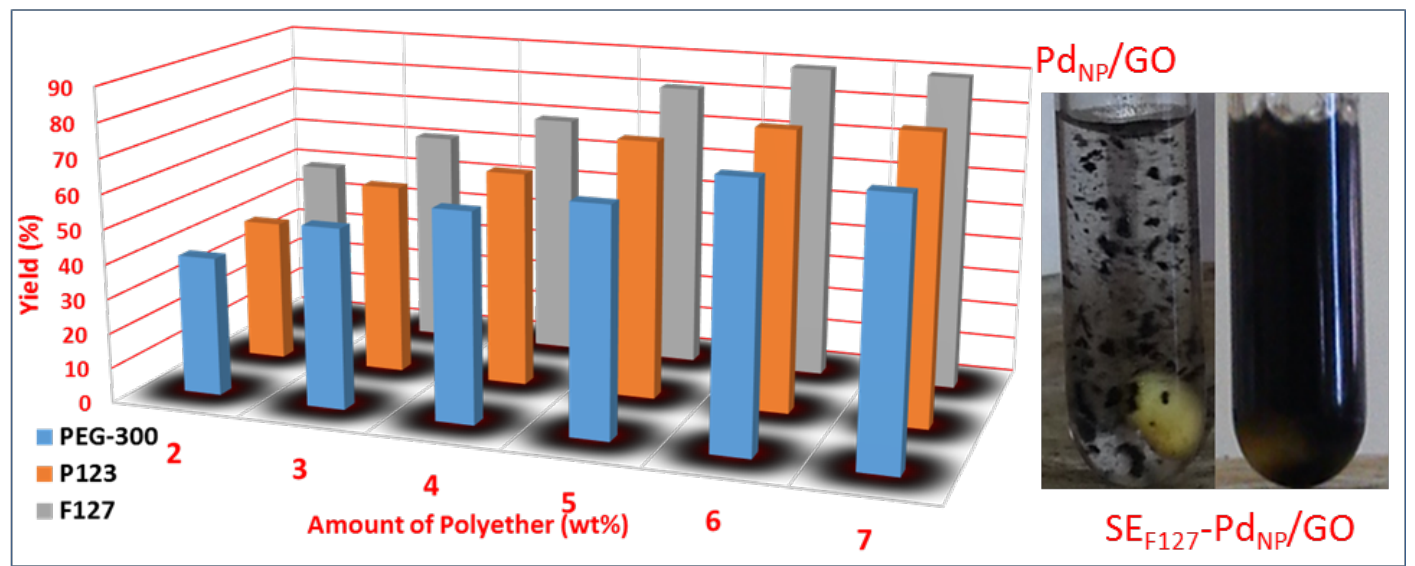

Fig. 5. Effect of surfactant type and amount on the catalytic activity of $\mathrm{Pd}($ nanoparticle)/GO in amidation of benzaldehyde $(1 \mathrm{mmol})$ and hydroxylamine hydrochloride $(1.5 \mathrm{mmol})$, potassium carbonate $(2.5 \mathrm{mmol})$ and $0.7 \mathrm{~mol} \% \mathrm{Pd}$ at $100{ }^{\circ} \mathrm{C}$ during $48 \mathrm{~h}$ in $2 \mathrm{~mL}$ DMSO mixture. In the presence of these three selected exfoliating agents, $\mathrm{Pd}$ (nanoparticle)/rGO was also put into examination. To our surprise, these polyethers had no remarkable exfoliating effect on the Pd supported reduced graphene oxide sheets at higher temperature. We observed that the higher 
temperature enhances the interactions of $\mathrm{rGO}$ sheets and polyethers are not capable of dominating these interactions. Therefore, we set aside the further study of $\mathrm{Pd}($ nanoparticle)/rGO catalytic behaviours in the amidation reaction.

Once investigation on the exfoliation effect of $\mathrm{Pd}($ nanoparticle)/GO was accomplished, we studied the other effective parameters on the catalytic behaviour of $\mathrm{Pd}($ nanoparticle)/GO in the presence of F127 (F127 surfactant exfoliated $\mathrm{Pd}($ nanoparticle $) / \mathrm{GO}=\mathrm{SE}_{\mathrm{F} 127^{-}}$ $\mathrm{Pd}($ nanoparticle)/GO). Scheme 1 indicates a general route to manufacture and use of catalyst in the amidation syntheses. The amidation reaction in this work is a cascade-type method for converting the benzaldehyde to benzamide. In this case, hydroxylamine hydrochloride is added to aldehyde and oxime forms initially. Then after a required reaction time, it converts to benzamide. And hence, we have developed the chemistry of primary amide synthesis by the catalysis of Pd nanoparticles which are supported onto GO sheets.

All reactions were optimized by benzaldehyde and $\mathrm{NH}_{2} \mathrm{OH} . \mathrm{HCl}$ as model reaction. Our attempt was to engage our catalytic system $\left(\mathrm{SE}_{\mathrm{F} 127}-\mathrm{Pd}(\right.$ nanoparticle $\left.) / \mathrm{GO}\right)$ for the synthesis of primary amides. Several parameters including base, solvent, and reaction time and temperature were carefully examined on this reaction. Some of them are represented in Table 1 . In this optimization, DMSO indicates excellent results compared to other solvents during $48 \mathrm{~h} . \mathrm{K}_{2} \mathrm{CO}_{3}$ and $\mathrm{Cs}_{2} \mathrm{CO}_{3}$ had mutual effect on the reaction yield. Therefore owing to economical reason, $\mathrm{K}_{2} \mathrm{CO}_{3}$ was preferred.

Once investigation of this matter, we studied the other effective parameters on the catalytic behavior of $\mathrm{Pd}($ nanoparticle)/GO in the presence of F127 (F127 surfactant exfoliated Pd/GO = $\mathrm{SE}_{\mathrm{F} 127}-\mathrm{Pd}($ nanoparticle)/GO). Scheme 1 indicates a general route to manufacture and use of catalyst in the amidation syntheses. The amidation reaction in this work is a cascade-type method 
for converting the benzaldehyde to benzamide. In this case, hydroxylamine hydrochloride is added to aldehyde and oxime forms initially. Then after a required reaction time, it converts to benzamide. And hence, we have developed the chemistry of primary amide synthesis by the catalysis of Pd nanoparticles which are supported onto GO sheets.

All reactions were optimized by benzaldehyde and $\mathrm{NH}_{2} \mathrm{OH} . \mathrm{HCl}$ as model reaction. Our attempt was to engage our catalytic system $\left(\mathrm{SE}_{\mathrm{F} 127^{-}} \mathrm{Pd}(\right.$ nanoparticle)/GO) for the synthesis of primary amides. Several parameters including base, solvent, and reaction time and temperature were carefully examined on this reaction. Some of them are represented in Table 1. In this optimization, DMSO indicates excellent results compared to other solvents during $48 \mathrm{~h} . \mathrm{K}_{2} \mathrm{CO}_{3}$ and $\mathrm{Cs}_{2} \mathrm{CO}_{3}$ had mutual effect on the reaction yield. Therefore owing to economical reasons, $\mathrm{K}_{2} \mathrm{CO}_{3}$ was preferred.

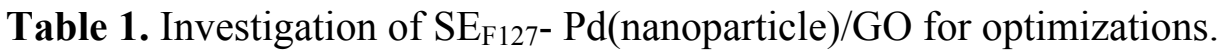

\begin{tabular}{|c|c|c|c|c|c|}
\hline Entry & Base & Solvent $^{\mathrm{a}}$ & Time (h) & $\mathrm{T}\left({ }^{\circ} \mathrm{C}\right)$ & Yield (\%) ${ }^{b}$ \\
\hline 1 & $\mathrm{~K}_{2} \mathrm{CO}_{3}$ & DMSO & 44 & 80 & 83 \\
\hline 2 & $\mathrm{~K}_{2} \mathrm{CO}_{3}$ & Toluene & 48 & 130 & Trace \\
\hline 3 & $\mathrm{~K}_{2} \mathrm{CO}_{3}$ & $\mathrm{H}_{2} \mathrm{O}$ & 100 & 100 & 70 \\
\hline 4 & $\mathrm{Na}_{2} \mathrm{CO}_{3}$ & DMSO & 100 & 130 & 82 \\
\hline 5 & $\mathrm{~K}_{2} \mathrm{CO}_{3}$ & DMSO & 48 & 120 & 90 \\
\hline 6 & $\mathrm{Cs}_{2} \mathrm{CO}_{3}$ & DMSO & 48 & 100 & 91 \\
\hline 7 & $\mathrm{KOH}$ & $\mathrm{DMSO} / \mathrm{H}_{2} \mathrm{O}$ & 72 & 100 & 34 \\
\hline 8 & $\mathrm{Cs}_{2} \mathrm{CO}_{3}$ & $\mathrm{DMSO} / \mathrm{H}_{2} \mathrm{O}$ & 72 & 120 & 74 \\
\hline 9 & $\mathrm{~K}_{2} \mathrm{CO}_{3}$ & $\mathrm{DMSO} / \mathrm{H}_{2} \mathrm{O}^{\mathrm{c}}$ & 72 & 120 & 71 \\
\hline
\end{tabular}

a) The solvents in this section were first used in the dispersion of $\mathrm{Pd} / \mathrm{GO}$ and then used in the reactions. ${ }^{\text {b) }}$ Isolated yields. ${ }^{\text {c) }} 0.5 \mathrm{~mL}$ of dispersed $\mathrm{SE}_{\mathrm{F} 127^{-}} \mathrm{Pd}$ (nanoparticle)/GO (containing 0.7 mol\% of Pd and $6 \mathrm{wt} \%$ of F127) was used per $1 \mathrm{mmol}$ of benzaldehyde, $1.5 \mathrm{~mL}$ DMSO was added in entry 9 (Other conditions include $1 \mathrm{mmol}$ of benzaldehyde, $1.5 \mathrm{mmol}$ of $\mathrm{NH}_{2} \mathrm{OH} . \mathrm{HCl}$, and the amount of base for each reaction test is $2.5 \mathrm{mmol}$ ). 
After finding the optimized conditions, other derivatives of primary amides were synthesized according to the optimized conditions. Accordingly, DMSO was selected as optimized solvent, F127 as a superior exfoliating agent and $\mathrm{K}_{2} \mathrm{CO}_{3}$ as the suitable base. Thus, other derivatives of benzamide were synthesized at $120{ }^{\circ} \mathrm{C}$ during $48-54 \mathrm{~h}$ (Table 2). Good to excellent yields of products were obtained using aromatic aldehydes bearing electron-donating (Table 2, entry 2-5) or electron-withdrawing (Table 2, entry 6-10) functional groups. Ortho-substituted aryl aldehydes (Table 2, entry 11) gave comparably lower isolated yields than those of parasubstituted compounds, which can be attributed to steric effects. Similar results were obtained with the reactions of heteroaromatic aldehydes including thiophene-2-carbaldehyde (Table 2, 12).

Table 2. Synthesis of primary benzamides under the catalysis of $\mathrm{SE}_{\mathrm{F} 127}-\mathrm{Pd}$ (nanoparticle)/GO. ${ }^{\text {a }}$

Entry


6

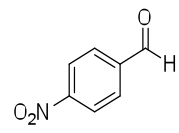

7

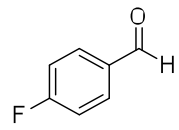

8

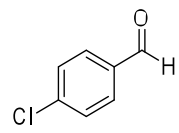

9

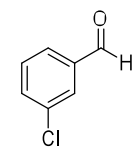

10

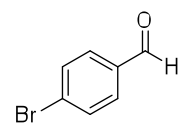

11

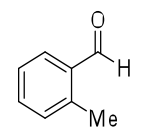

12

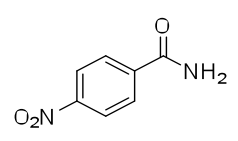

48

90<smiles>NC(=O)c1ccc(Cl)cc1</smiles>

48

84

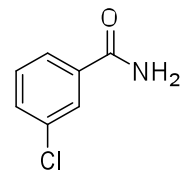

48

86

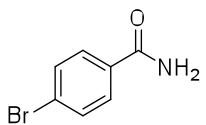

48

61

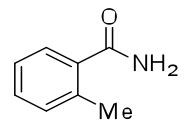

50

74

48
81

${ }^{\mathrm{a}}$ Reaction conditions include $1 \mathrm{mmol}$ of benzaldehyde, $1.5 \mathrm{mmol}$ of $\mathrm{NH}_{2} \mathrm{OH} . \mathrm{HCl}, 2.5 \mathrm{mmol}$ of $\mathrm{K}_{2} \mathrm{CO}_{3}, 0.5 \mathrm{~mL}$ water dispersed $\mathrm{SE}_{\mathrm{F} 127}-\mathrm{Pd}($ nanoparticle)/GO (Pd, $0.7 \mathrm{~mol} \%$ and $\mathrm{F} 127,6 \mathrm{wt} \%)$ in the presence of $1.5 \mathrm{~mL} \mathrm{DMSO}$ at $120^{\circ} \mathrm{C}$.

F127 was found to be more versatile and efficient for this system and therefore, all $\mathrm{Pd}($ nanoparticle)/rGO exfoliations during the amidation reactions were performed by F127. The yields were comparable with that of homogenous $\mathrm{Pd}^{2+}$ which is previously reported [38]. This comparison indicate a competitable results of the heterogeneous catalyst against homogeneous Pd species.

It is to be noted here that for iodine derivative of benzaldehyde, when we performed the reaction with p-iodobenzaldehyde under the optimized conditions, the main product was homo-coupled biaryl compound (Scheme 3). 


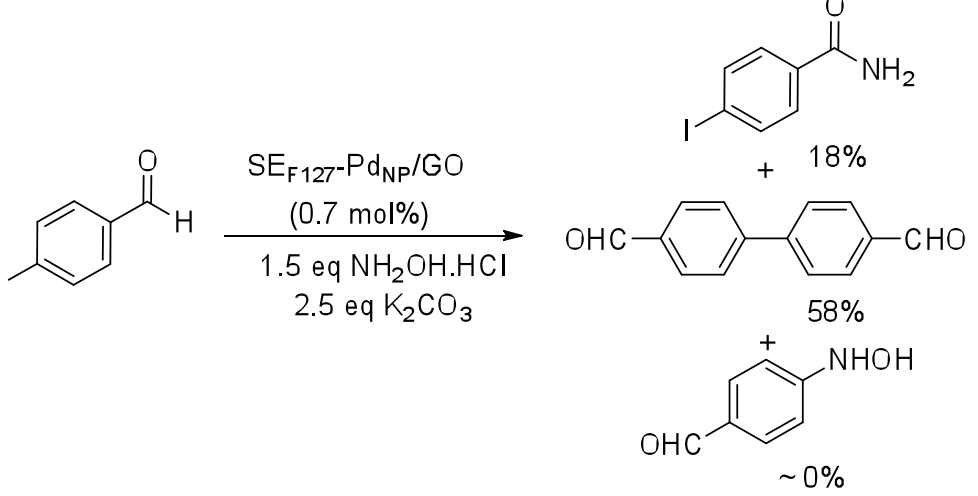

Scheme 3. Application of $p$-iodobenzaldehyde for amidation test.

Recyclability study of $\mathrm{Pd}\left(\right.$ nanoparticle)/GO in amidation with benzaldehyde and $\mathrm{NH}_{2} \mathrm{OH}$ as representative for other derivatives were investigated in further step. This investigation demonstrated that the catalyst except F127 has ability to be recovered and reused at least for 8 runs. Figure 6 exhibits obtained yields in each run for each method and 8th run TEM image in which the major ratio of $\mathrm{Pd}^{2+}$ ions has been reduced converted to aggregated $\mathrm{Pd}$ nanoparticles. As a result, the related decrease in yields after several runs can be attributed to aggregation of Pd nanoparticles and subsequently, its catalytic deactivation. Atomic absorptions spectroscopy (AAS) results also reveals no significant leaching of Pd (less than $10 \mathrm{wt} \%$ from total amount of $\mathrm{Pd}$ in $\mathrm{Pd} / \mathrm{GO}$ ) from the surface of graphene oxide.
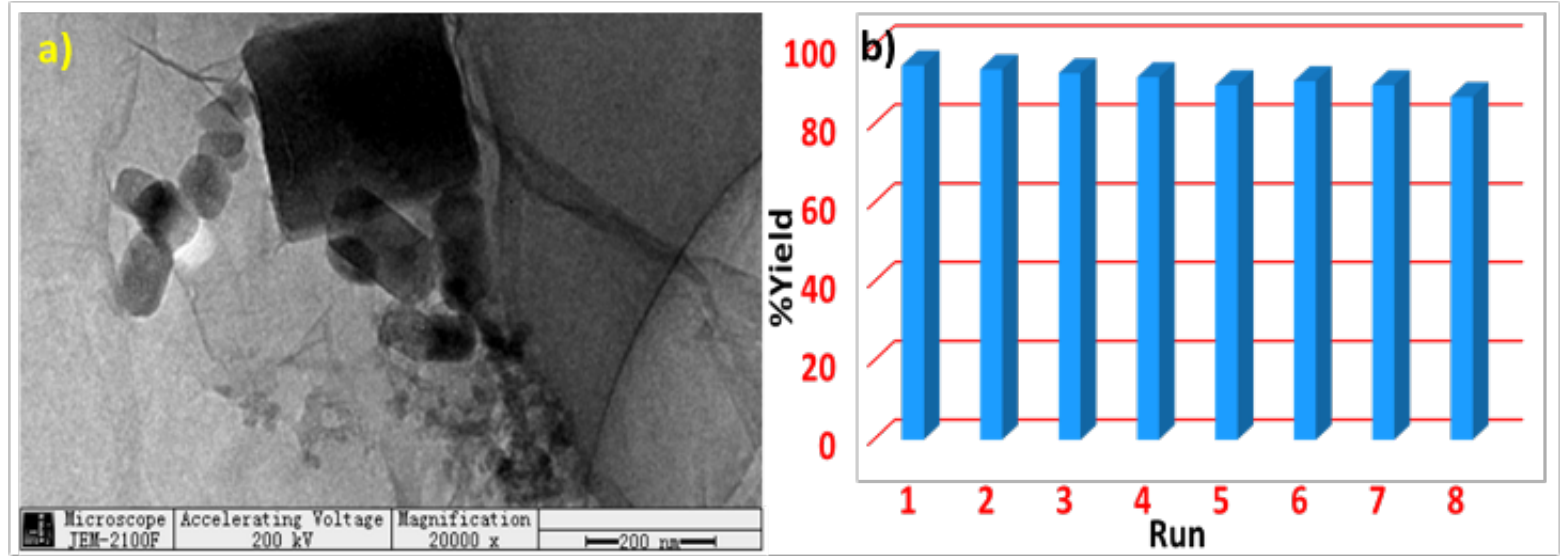

Fig. 6. a) TEM image of $\operatorname{Pd}\left(\right.$ nanoparticle)/GO after $8^{\text {th }}$ run. b) Recyclability study of $\mathrm{Pd}\left(\right.$ nanoparticle)/GO in amidation with benzaldehyde $(5 \mathrm{mmol})$ and $\mathrm{NH}_{2} \mathrm{OH} . \mathrm{HCl}(7.5 \mathrm{mmol})$ and 
$\mathrm{K}_{2} \mathrm{CO}_{3}(12.5 \mathrm{mmol})$ in the presence of $\mathrm{Pd}($ nanoparticle $) / \mathrm{GO} / \mathrm{F} 127[\mathrm{Pd}(0.7 \mathrm{~mol} \%)$ and F127 (6 $\mathrm{wt} \%)$ ] during $48 \mathrm{~h}$ at $120^{\circ} \mathrm{C}$.

Due to the fact that there are few reports for these reactions with palladium and we haven't investigated the exact mechanism of amidations, we have speculate a possible mechanism for this process. On the other hand, there are some mechanistic studies and reports that can reinforce our proposed mechanisms $[17,41,42]$. The mechanism (see SI) indicate two possible pathways to amide products. In the previous reports, it is claimed that because the labeled oxygen atom on hydroxyl amine finally appears at carbonyl oxygen of the product, amide, the pathway of mechanism is majorly pass through path 2 , where a cyclic intermediate forms [43]. This proposed mechanism is mostly for transition metal catalyzed conversion of aldoxime to primary amide.

Also, the catalytic system was compared by other catalysts in this cascade amidation of benzaldehyde with hydroxylamine hydrochloride (Table 3). This study demonstrated that $\mathrm{SE}_{\mathrm{F} 127^{-}}$ $\operatorname{Pd}($ nanoparticle)/GO has superior activity rather to other types of Pd supported catalysts. Based on this test, $\mathrm{Pd}($ nanoparticle)/GO was more active than $\mathrm{Pd}($ nanoparticle)/rGO which can be due to the fast aggregation of $\mathrm{rGO}$ sheets at higher temperature in the presence of reactants. Aggregation cause to entrapment of Pd between rGO sheets. In this study, there was $94 \%$ of the reactant conversion in which the only $4 \%$ of it stopped in aldoxime which shows a higher selectivity towards the product.

Table 3. Catalytic comparison of Pd species in the amidation. ${ }^{a}$

\begin{tabular}{|c|c|c|c|c|c|}
\hline Entry & Catalyst & Time & Conv. & Yield & \\
\hline
\end{tabular}




\begin{tabular}{llcccc}
\hline & & $(\mathrm{h})$ & $(\%)$ & $(\%)^{\mathrm{b}}$ & \\
\hline 1 & $\mathrm{Pd} / \mathrm{C}(10 \mathrm{wt} \%)$ & 10 & 70 & 50 & {$[44]$} \\
2 & $\mathrm{SBA}-15 / \mathrm{PrEn}-\mathrm{Cu}$ & 10 & 90 & 70 & {$[44]$} \\
3 & $\mathrm{SE}_{\mathrm{F} 127-\mathrm{Pd} / \mathrm{GO}}$ & 72 & 94 & 90 & This work $^{\mathrm{c}}$ \\
4 & $\mathrm{SE}_{\mathrm{F} 127-\mathrm{Pd} / \mathrm{rGO}}$ & 72 & 92 & 35 & This work \\
\hline
\end{tabular}

${ }^{a}$ Reaction is under optimum conditions. ${ }^{b}$ Isolated yields. ${ }^{c}$ Similar to preparation procedure of $\mathrm{SE}_{\mathrm{F} 127}-\mathrm{Pd} / \mathrm{rGO}$.

\section{Conclusion}

$\mathrm{Pd}($ nanoparticle)/GO as a first Pd-supported nanocatalyst was applied in the cascade synthesis of amides through the reaction of aromatic aldehyde and $\mathrm{NH}_{2} \mathrm{OH} . \mathrm{HCl}$ in oxime formation and then beckman rearrangement in one-pot conditions. GO sheets were highly exfoliated during the catalysis through various polyethers and converted to a highly dispersive heterogeneous nanocatalysts. Among polyethers, F127 acted better in the results and exfoliation behaviour. This catalytic system was successfully applied as a relaively green, recyclable, and efficient system incascade primary amide synthesis and single-pot amidation. Cascade reactions were advantageous to their non-cascade corresponding reactions. Some possible mechanisms were proposed for cascade amidation of aromatic aldehydes.

\section{Experimental}

\section{Experimental and Catalyst Characterization}

All reagents were purchased from Merck (Germany), Fluka (Switzerland) and Sigma-Aldrich and used without further purification. A multi-wave ultrasonic generator (Sonicator-3000; Misonix Inc., Farmingdale, NY, USA), equipped with a converter/transducer and titanium oscillator (horn). GC analyses was recorded on GC Chrom (Teif Gostar Faraz Co., Iran) 
Preparation of SE- $\mathrm{Pd}($ nanoparticle $) / \mathrm{GO}$

Graphite oxide was prepared from graphite according to the Hummers method [45]. Briefly, graphite was oxidized by treating with $\mathrm{KMnO}_{4}$ and $\mathrm{NaNO}_{3}$ in concentrated $\mathrm{H}_{2} \mathrm{SO}_{4}$ to form graphite oxide, and $2 \mathrm{~g}$ of the obtained graphite oxide was exfoliated into graphene oxide (GO) by $400 \mathrm{~mL}$ of water under sonication for $2 \mathrm{~h}$. The conductivity of GO sheets after sonication was $5700{\mathrm{~S} . \mathrm{cm}^{-1}}^{-1}$ After sonication, a solution of $\mathrm{PdCl}_{2}(0.12 \mathrm{~g}$ in $5 \mathrm{~mL}$ saline solution) was added to mixture in the presence of ultrasonic irradiation for $2 \mathrm{~h}$. The purified Pd(nanoparticle)/GO (2 g) was quickly dispersed in F127/DMSO solution for further use as the catalyst [2 g $\mathrm{Pd}($ nanoparticle) $/ \mathrm{GO}$ in $50 \mathrm{~mL}$ pure $\mathrm{DMSO}$ in the presence of polyether $(6 \mathrm{wt} \%)]$. The amount of Pd loaded on GO sheets was measured by AAS which was $3.8 \mathrm{wt} \%$.

\section{Preparation of SE-Pd(nanoparticle)/rGO}

Synthesis of SE-Pd(nanoparticle)/rGO was achieved according to SE-Pd(nanoparticle)/GO procedure except $\mathrm{GO}$ was first reduced to $\mathrm{rGO}$ by required amount of $\mathrm{NaBH}_{4}$. After separation and washing rGO, it was applied for Pd supporting and the dispersion was prepared according to procedure of SE-Pd(nanoparticle)/GO.

\section{General procedure for synthesis of primary amides from aldehyde}

In a typical method, benzaldehyde $(1.0 \mathrm{mmol})$, hydroxylamine hydrochloride $(1.5 \mathrm{mmol})$, potassium carbonate $(2.5 \mathrm{mmol})$ and $0.5 \mathrm{~mL}$ of as-prepared $\mathrm{SE}_{\mathrm{F} 127^{-}} \mathrm{Pd}($ nanoparticle $) / \mathrm{GO}$ in DMSO were added to reaction media in the presence of $1.5 \mathrm{~mL}$ DMSO. The reaction was allowed to stir at $120^{\circ} \mathrm{C}$. Upon reaction completion, the catalyst was separated by centrifuge and 
the organic residue was extracted with dichloromethane and evaporated under reduced pressure.

The organic residue was purified by column chromatography. All yields were reported based on isolated amount. All products are known and identified by ${ }^{1} \mathrm{H}-\mathrm{NMR},{ }^{13} \mathrm{C}-\mathrm{NMR}$ spectrum and physical properties.

\section{Acknowledgement}

The authors would like to thanks for financial support from Iran National Science Foundation (INSF).

\section{Supplementary data}

Supplementary Information (SI) of this article can be found, in the online version, at www.elsevier.com.

\section{References}

[1] M.B. Gawande, A.K. Rathi, I.D. Nogueira, R.S. Varma, P.S. Branco, Magnetite-supported sulfonic acid: a retrievable nanocatalyst for the Ritter reaction and multicomponent reactions, Green Chemistry, 15 (2013) 1895-1899.

[2] C.L. Allen, J.M.J. Williams, Metal-catalysed approaches to amide bond formation, Chemical Society Reviews, 40 (2011) 3405-3415.

[3] P. Crochet, V. Cadierno, Catalytic synthesis of amides via aldoximes rearrangement, Chemical Communications, 51 (2015) 2495-2505.

[4] K. Sasaki, D. Crich, Facile Amide Bond Formation from Carboxylic Acids and Isocyanates, Organic Letters, 13 (2011) 2256-2259.

[5] X.-F. Wu, M. Sharif, A. Pews-Davtyan, P. Langer, K. Ayub, M. Beller, The First ZnIICatalyzed Oxidative Amidation of Benzyl Alcohols with Amines under Solvent-Free Conditions, European Journal of Organic Chemistry, 2013 (2013) 2783-2787.

[6] X. Liu, K.F. Jensen, Direct oxidative amidation of aromatic aldehydes using aqueous hydrogen peroxide in continuous flow microreactor systems, Green Chemistry, 14 (2012) 14711474.

[7] S. Gaspa, A. Porcheddu, L. De Luca, Iron-catalysed oxidative amidation of alcohols with amines, Organic \& Biomolecular Chemistry, 11 (2013) 3803-3807.

[8] R. Deshidi, M. Kumar, S. Devari, B.A. Shah, A general metal free approach to [small alpha]ketoamides via oxidative amidation-diketonization of terminal alkynes, Chemical Communications, 50 (2014) 9533-9535.

[9] S. Rostamnia, E. Doustkhah, Increased SBA-15-SO3H Catalytic Activity through Hydrophilic/Hydrophobic Fluoroalkyl-Chained Alcohols (RFOH/SBA-15-Pr-SO3H), Synlett, 26 (2015) 1345-1347. 
[10] A.K. Rathi, M.B. Gawande, V. Ranc, J. Pechousek, M. Petr, K. Cepe, R.S. Varma, R. Zboril, Continuous flow hydrogenation of nitroarenes, azides and alkenes using maghemite-Pd nanocomposites, Catalysis Science \& Technology, 6 (2016) 152-160.

[11] S. Rostamnia, X. Liu, D. Zheng, Ordered interface mesoporous immobilized Pd precatalyst: En/Pd complexes embedded inside the SBA-15 as an active, reusable and selective phosphine-free hybrid catalyst for the water medium Heck coupling process, Journal of Colloid and Interface Science, 432 (2014) 86-91.

[12] S. Rostamnia, K. Lamei, F. Pourhassan, Generation of uniform and small particle size of palladium onto the SH-decorated SBA-15 pore-walls: SBA-15/(SH)XPd-NPY as a recoverable nanocatalyst for Suzuki-Miyaura coupling reaction in air and water, RSC Advances, 4 (2014) 59626-59631.

[13] S. Rostamnia, B. Zeynizadeh, E. Doustkhah, H.G. Hosseini, Exfoliated Pd decorated graphene oxide nanosheets (PdNP-GO/P123): Non-toxic, ligandless and recyclable in greener Hiyama cross-coupling reaction, Journal of Colloid and Interface Science, 451 (2015) 46-52.

[14] S. Rostamnia, H. Golchin Hossieni, E. Doustkhah, Homoleptic chelating N-heterocyclic carbene complexes of palladium immobilized within the pores of SBA-15/IL (NHC-Pd@SBA15/IL) as heterogeneous catalyst for Hiyama reaction, Journal of Organometallic Chemistry, 791 (2015) 18-23.

[15] S. Rostamnia, E. Doustkhah, Z. Karimi, S. Amini, R. Luque, Surfactant-Exfoliated Highly Dispersive Pd-Supported Graphene Oxide Nanocomposite as a Catalyst for Aerobic Aqueous Oxidations of Alcohols, ChemCatChem, 7 (2015) 1678-1683.

[16] S. Sa, M.B. Gawande, A. Velhinho, J.P. Veiga, N. Bundaleski, J. Trigueiro, A. Tolstogouzov, O.M.N.D. Teodoro, R. Zboril, R.S. Varma, P.S. Branco, Magnetically recyclable magnetite-palladium (Nanocat-Fe-Pd) nanocatalyst for the Buchwald-Hartwig reaction, Green Chemistry, 16 (2014) 3494-3500.

[17] Y. Suto, N. Yamagiwa, Y. Torisawa, Pd-catalyzed oxidative amidation of aldehydes with hydrogen peroxide, Tetrahedron Letters, 49 (2008) 5732-5735.

[18] X. Liu, K.K. Hii, Oxidative Amidation of Activated Alkenes Using Pd(OAc)2 as a Catalyst Precursor, European Journal of Organic Chemistry, 2010 (2010) 5181-5189.

[19] L. Zhang, W. Wang, A. Wang, Y. Cui, X. Yang, Y. Huang, X. Liu, W. Liu, J.-Y. Son, H. Oji, T. Zhang, Aerobic oxidative coupling of alcohols and amines over $\mathrm{Au}-\mathrm{Pd} / \mathrm{resin}$ in water: $\mathrm{Au} / \mathrm{Pd}$ molar ratios switch the reaction pathways to amides or imines, Green Chemistry, 15 (2013) 2680-2684.

[20] A.K. Rathi, M.B. Gawande, J. Pechousek, J. Tucek, C. Aparicio, M. Petr, O. Tomanec, R. Krikavova, Z. Travnicek, R.S. Varma, R. Zboril, Maghemite decorated with ultra-small palladium nanoparticles ([gamma]-Fe2O3-Pd): applications in the Heck-Mizoroki olefination, Suzuki reaction and allylic oxidation of alkenes, Green Chemistry, (2016).

[21] M.J. Gronnow, R. Luque, D.J. Macquarrie, J.H. Clark, A novel highly active biomaterial supported palladium catalyst, Green Chemistry, 7 (2005) 552-557.

[22] A. Yepez, J.M. Hidalgo, A. Pineda, R. Cerny, P. Jisa, A. Garcia, A.A. Romero, R. Luque, Mechanistic insights into the hydroconversion of cinnamaldehyde using mechanochemicallysynthesized Pd/Al-SBA-15 catalysts, Green Chemistry, 17 (2015) 565-572.

[23] S. Rostamnia, E. Doustkhah, B. Zeynizadeh, Cationic modification of SBA-15 pore walls for Pd supporting: Pd@SBA-15/ILDABCO as a catalyst for Suzuki coupling in water medium, Microporous and Mesoporous Materials, 222 (2016) 87-93. 
[24] S. Rostamnia, E. Doustkhah, R. Bulgar, B. Zeynizadeh, Supported palladium ions inside periodic mesoporous organosilica with ionic liquid framework (Pd@IL-PMO) as an efficient green catalyst for S-arylation coupling, Microporous and Mesoporous Materials, 225 (2016) 272279.

[25] S. Rostamnia, E. Doustkhah, H. Golchin-Hosseini, B. Zeynizadeh, H. Xin, R. Luque, Efficient tandem aqueous room temperature oxidative amidations catalysed by supported $\mathrm{Pd}$ nanoparticles on graphene oxide, Catalysis Science \& Technology, (2016).

[26] Z. Yan, M. Zhang, J. Xie, P.K. Shen, Vanadium carbide and graphite promoted Pd electrocatalyst for ethanol oxidation in alkaline media, Journal of Power Sources, 243 (2013) 336-342.

[27] S. Bawaked, Q. He, N.F. Dummer, A.F. Carley, D.W. Knight, D. Bethell, C.J. Kiely, G.J. Hutchings, Selective oxidation of alkenes using graphite-supported gold-palladium catalysts, Catalysis Science \& Technology, 1 (2011) 747-759.

[28] D. Appy, H. Lei, C.-Z. Wang, M.C. Tringides, D.-J. Liu, J.W. Evans, P.A. Thiel, Transition metals on the $\left(\begin{array}{llll}0 & 0 & 0 & 1\end{array}\right)$ surface of graphite: Fundamental aspects of adsorption, diffusion, and morphology, Progress in Surface Science, 89 (2014) 219-238.

[29] W. Xu, X. Wang, Q. Zhou, B. Meng, J. Zhao, J. Qiu, Y. Gogotsi, Low-temperature plasmaassisted preparation of graphene supported palladium nanoparticles with high hydrodesulfurization activity, Journal of Materials Chemistry, 22 (2012) 14363-14368.

[30] H. Huang, X. Wang, Pd nanoparticles supported on low-defect graphene sheets: for use as high-performance electrocatalysts for formic acid and methanol oxidation, Journal of Materials Chemistry, 22 (2012) 22533-22541.

[31] V. Sharavath, S. Ghosh, Palladium nanoparticles on noncovalently functionalized graphenebased heterogeneous catalyst for the Suzuki-Miyaura and Heck-Mizoroki reactions in water, RSC Advances, 4 (2014) 48322-48330.

[32] S.S. Shendage, A.S. Singh, J.M. Nagarkar, Facile approach to the electrochemical synthesis of palladium-reduced graphene oxide and its application for Suzuki coupling reaction, Tetrahedron Letters, 55 (2014) 857-860.

[33] A. Martínez-Asencio, M. Yus, D.J. Ramón, Copper(II) acetate-catalyzed one-pot conversion of aldehydes into primary amides through a Beckmann-type rearrangement, Tetrahedron, 68 (2012) 3948-3951.

[34] C.L. Allen, C. Burel, J.M.J. Williams, Cost efficient synthesis of amides from oximes with indium or zinc catalysts, Tetrahedron Letters, 51 (2010) 2724-2726.

[35] N.A. Owston, A.J. Parker, J.M.J. Williams, Highly Efficient Ruthenium-Catalyzed Oxime to Amide Rearrangement, Organic Letters, 9 (2007) 3599-3601.

[36] M. Kim, J. Lee, H.-Y. Lee, S. Chang, Significant Self-Acceleration Effects of Nitrile Additives in the Rhodium-Catalyzed Conversion of Aldoximes to Amides: A New Mechanistic Aspect, Advanced Synthesis \& Catalysis, 351 (2009) 1807-1812.

[37] R.S. Ramón, J. Bosson, S. Díez-González, N. Marion, S.P. Nolan, Au/Ag-Cocatalyzed Aldoximes to Amides Rearrangement under Solvent- and Acid-Free Conditions, The Journal of Organic Chemistry, 75 (2010) 1197-1202.

[38] M.A. Ali, T. Punniyamurthy, Palladium-Catalyzed One-Pot Conversion of Aldehydes to Amides, Advanced Synthesis \& Catalysis, 352 (2010) 288-292.

[39] B.F. Machado, P. Serp, Graphene-based materials for catalysis, Catalysis Science \& Technology, 2 (2012) 54-75. 
[40] S.S. Kulthe, N.N. Inamdar, Y.M. Choudhari, S.M. Shirolikar, L.C. Borde, V.K. Mourya, Mixed micelle formation with hydrophobic and hydrophilic Pluronic block copolymers: Implications for controlled and targeted drug delivery, Colloids and Surfaces B: Biointerfaces, 88 (2011) 691-696.

[41] S. Yang, H. Yan, X. Ren, X. Shi, J. Li, Y. Wang, G. Huang, Copper-catalyzed dehydrogenative reaction: synthesis of amide from aldehydes and aminopyridine, Tetrahedron, 69 (2013) 6431-6435.

[42] S. Rostamnia, N. Nouruzi, H. Xin, R. Luque, Efficient and selective copper-grafted nanoporous silica in aqueous conversion of aldehydes to amides, Catalysis Science \& Technology, 5 (2015) 199-205.

[43] C.L. Allen, R. Lawrence, L. Emmett, J.M.J. Williams, Mechanistic Studies into MetalCatalyzed Aldoxime to Amide Rearrangements, Advanced Synthesis \& Catalysis, 353 (2011) 3262-3268.

[44] S. Rostamnia, H. Xin, Pd(OAc)2@SBA-15/PrEn nanoreactor: a highly active, reusable and selective phosphine-free catalyst for Suzuki-Miyauracross-coupling reaction in aqueous media, Applied Organometallic Chemistry, 27 (2013) 348-352.

[45] W.S. Hummers, R.E. Offeman, Preparation of Graphitic Oxide, Journal of the American Chemical Society, 80 (1958) 1339-1339. 